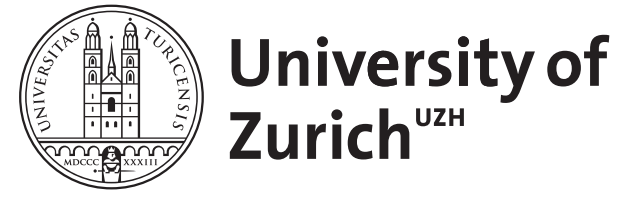

\title{
The material side of virtualization
}

\author{
Hilty, Lorenz M
}

\begin{abstract}
The Environmental Informatics community could recently celebrate its 20th anniversary. The application of Information and Communication Technology (ICT) to problems of environmental research and management has made considerable progress and contributes to sustainable development. Moreover, ICT has the potential to virtualize processes that would otherwise consume considerable amounts of material and energy; virtual meetings, for instance, could avoid 97-98\% of the CO2 emissions of physical meetings. The time, space, material and energy needed to provide a unit of ICT service have roughly decreased by a factor of 1000 since the first PC was sold. It seems therefore natural that researchers and industries using ICT in the environmental field ignore the environmental impacts caused by ICT hardware ndash; they are just negligible compared to the environmental benefits that can be realized with the applications.Paradoxically, it is the progress in ICT hardware efficiency that has made ICT a part of the problem, too. The global mass and energy flows caused throughout the hardware life cycle are increasing due to the wide-spread use of ICT products and their decreasing useful lives. The environmental problems caused by the production, use and disposal of ICT hard-ware are solvable in principle; they are not as hard as the discrepancy between - e.g. - growing mobility and CO2 reduction goals. But problems can only be solved if they are not neglected.
\end{abstract}

DOI: https://doi.org/10.1007/978-3-540-71335-7_3

Posted at the Zurich Open Repository and Archive, University of Zurich

ZORA URL: https://doi.org/10.5167/uzh-61204

Conference or Workshop Item

Accepted Version

Originally published at:

Hilty, Lorenz M (2007). The material side of virtualization. In: ITEE 2007, Oldenburg, Germany, 23 January 2007. Springer, 5-6.

DOI: https://doi.org/10.1007/978-3-540-71335-7_3 


\title{
The Material Side of Virtualization
}

\author{
Lorenz M. Hilty
}

Technology and Society Lab, Empa Swiss Federal Laboratories for Materials Testing and Research, Lerchenfeldstr. 5, CH-9014 St.Gallen

The Environmental Informatics community could recently celebrate its 20th anniversary (Tochtermann et al. 2006, Hilty et al. 2006a). The application of Information and Communication Technology (ICT) to problems of environmental research and management has made considerable progress and contributes to sustainable development (Hilty et al. 2004a). Moreover, ICT has the potential to virtualize processes that would otherwise consume considerable amounts of material and energy; virtual meetings, for instance, could avoid 97-98\% of the $\mathrm{CO}_{2}$ emissions of physical meetings (Hischier and Hilty 2002).

The time, space, material and energy needed to provide a unit of ICT service have roughly decreased by a factor of 1000 since the first PC was sold. It seems therefore natural that researchers and industries using ICT in the environmental field ignore the environmental impacts caused by ICT hardware - they are just negligible compared to the environmental benefits that can be realized with the applications.

Paradoxically, it is the progress in ICT hardware efficiency that has made ICT a part of the problem, too. The global mass and energy flows caused throughout the hardware life cycle are increasing due to the widespread use of ICT products and their decreasing useful lives. The environmental problems caused by the production, use and disposal of ICT hardware are solvable in principle; they are not as hard as the discrepancy betweeen - e.g. - growing mobility and $\mathrm{CO}_{2}$ reduction goals. But problems can only be solved if they are not neglected.

The Technology and Society Lab at Empa has explored some environmental and social aspects of ICT production, use and disposal at a global scale under the umbrella of the "Sustainability in the Information Society" research program funded by the ETH Board. This research was based on 
Life Cycle Assessment (LCA) studies, prospective Technology Assessment (TA) studies and technology cooperation projects with partners in emerging economies (China, India and South Africa). These projects have identified the following issues:

- Production: The scarcity of some chemical elements (e.g. Indium used for LCDs) may constrain some development paths in the near future.

- Use: The overall energy demand of ICT infrastructure tends to increase, but it is possible to go against this trend.

- Disposal: There is a huge informal electronics recycling sector in Asia with relevant health and environmental impacts (Hilty 2005). Recycling systems as they have been implemented in Switzerland and now in the EU (WEEE directive), are indispensable because electronic waste contains toxic as well as valuable substances. However, miniaturization of devices and the trend towards pervasive computing (Hilty et al. 2004b) create new challenges for electronic waste recycling. In the long run, ICT industry will have to find ways to avoid toxic and scarce materials.

The vision of a sustainable information society, i.e. a society which virtualizes those processes that are no longer acceptable for ecological reasons and keeps the material side-effects of ICT small at the same time - such a vision is not completely unrealistic. However, using more ICT does not automatically "create" a sustainable information society, as our observations and models clearly show (Hilty et al. 2006b). Political strategies are needed if ICT is to serve sustainability.

\section{References}

Hilty LM, Seifert EK, Treibert R (eds., 2004a) Information Systems for Sustainable Development. Idea Group Publishing, Hershey

Hilty LM, Som C, Köhler A (2004b) Assessing the Human, Social, and Environmental Risks of Pervasive Computing. Hum Ecol Risk Assess 10(5):853-874

Hilty LM (ed., 2005) Environmental and Social Impacts of Electronic Waste Recycling. Special issue. Environmental Impact Assessment Review 25(5)

Hilty LM, Page B, Hrebicek J (eds., 2006a) Environmental Informatics. Special issue. Environmental Modelling \& Software 21(11)

Hilty LM, Arnfalk P, Erdmann L, Goodman J, Lehmann M, Wäger P (2006b) The Relevance of Information and Communication Technologies for Environmental Sustainability - a Prospective Simulation Study. Environmental Modelling \& Software 21(11):1618-1629

Hischier R, Hilty LM (2002) Environmental impacts of an international conference. Environmental Impact Assessment Review 22(5):543-557

Tochtermann K, Scharl A (eds., 2006) EnviroInfo 2006. Managing Environmental Knowledge. Shaker-Verlag 